Supplemental Table 1

Time 1 Characteristics of Adults with ASD

\begin{tabular}{|c|c|c|}
\hline & $\mathrm{N}$ & Percent \\
\hline \multicolumn{3}{|l|}{ Age category of son/daughter with ASD } \\
\hline $18-24$ years & 49 & $30.4 \%$ \\
\hline $25-29$ years & 40 & $24.8 \%$ \\
\hline $30-34$ years & 27 & $16.8 \%$ \\
\hline $35-39$ years & 15 & $9.3 \%$ \\
\hline $40-44$ years & 16 & $9.9 \%$ \\
\hline $45-49$ years & 13 & $8.1 \%$ \\
\hline $50-52$ years & 1 & $0.6 \%$ \\
\hline \multicolumn{3}{|l|}{ Sex } \\
\hline Men & 116 & $72.0 \%$ \\
\hline Women & 45 & $28.0 \%$ \\
\hline \multicolumn{3}{|l|}{ Intellectual disability diagnosis } \\
\hline Yes & 130 & $80.7 \%$ \\
\hline No & 31 & $19.3 \%$ \\
\hline \multicolumn{3}{|l|}{ Level of language (from ADI-R) } \\
\hline Daily functional use & 112 & $69.6 \%$ \\
\hline No functional use of 3-word phrases & 20 & $12.4 \%$ \\
\hline Fewer than 5 words/speech not used daily & 29 & $18.0 \%$ \\
\hline \multicolumn{3}{|l|}{ Living Arrangements } \\
\hline Co-residing with parents & 64 & $39.8 \%$ \\
\hline Community residence & 68 & $42.2 \%$ \\
\hline Semi-independent living & 17 & $10.6 \%$ \\
\hline Independent living & 5 & $3.1 \%$ \\
\hline Public or private institution & 5 & $3.1 \%$ \\
\hline Foster home & 1 & $0.6 \%$ \\
\hline Living with other relatives & 1 & $0.6 \%$ \\
\hline \multicolumn{3}{|l|}{ Ever received a diagnosis of: } \\
\hline Autism & 154 & $95.7 \%$ \\
\hline Asperger's syndrome & 16 & $9.9 \%$ \\
\hline PDD-NOS & 29 & $18.0 \%$ \\
\hline Attention deficit disorder & 30 & $18.6 \%$ \\
\hline Bi-polar disorder & 13 & 8.1 \\
\hline Cerebral palsy & 7 & $4.3 \%$ \\
\hline Epilepsy/Seizure disorder & 50 & $31.1 \%$ \\
\hline Schizophrenia & 12 & $7.5 \%$ \\
\hline Obsessive compulsive disorder & 41 & $25.5 \%$ \\
\hline Depression & 22 & $13.7 \%$ \\
\hline Anxiety & 34 & $21.1 \%$ \\
\hline \multicolumn{3}{|l|}{ Level of maladaptive behaviors (from SIB-R) } \\
\hline Normal & 75 & $46.6 \%(49.7 \%)$ \\
\hline Marginal & 45 & $28.0 \%(29.8 \%)$ \\
\hline
\end{tabular}




\begin{tabular}{|c|c|c|}
\hline & $\mathrm{N}$ & Percent \\
\hline Moderate & 24 & $14.9 \%(15.9 \%)$ \\
\hline Serious & 3 & $1.9 \% \quad(2.0 \%)$ \\
\hline Very serious & 4 & $2.5 \% \quad(2.6 \%)$ \\
\hline Missing & 10 & 6.2 \\
\hline \multicolumn{3}{|l|}{ Family household income (\$) } \\
\hline 9,999 or less & 2 & $1.2 \% \quad(1.4 \%)$ \\
\hline 10,000 to 19,999 & 19 & $11.8 \%(12.8 \%)$ \\
\hline 20,000 to 29,999 & 26 & $16.1 \%(17.6 \%)$ \\
\hline 30,000 to 39,999 & 23 & $14.3 \%(15.5 \%)$ \\
\hline 40,000 to 49,999 & 16 & $9.9 \% \quad(10.8 \%)$ \\
\hline 50,000 to 59,999 & 5 & $3.1 \% \quad(3.4 \%)$ \\
\hline 60,000 to 69,999 & 14 & $8.7 \% \quad(9.5 \%)$ \\
\hline 70,000 or greater & 43 & $26.7 \%(29.1 \%)$ \\
\hline Missing & 13 & $8.1 \%$ \\
\hline \multicolumn{3}{|l|}{ Number of services received } \\
\hline 0 & 4 & $2.5 \%$ \\
\hline $1-3$ & 34 & $21.1 \%$ \\
\hline $4-6$ & 83 & $51.6 \%$ \\
\hline $7-9$ & 33 & $20.5 \%$ \\
\hline 10 or more & 7 & $4.3 \%$ \\
\hline \multicolumn{3}{|l|}{ Number of unmet service needs } \\
\hline 0 & 46 & $28.6 \%$ \\
\hline $1-3$ & 81 & $50.3 \%$ \\
\hline $4-6$ & 30 & $18.6 \%$ \\
\hline $7-9$ & 4 & $2.5 \%$ \\
\hline 10 or more & 0 & $0 \%$ \\
\hline \multicolumn{3}{|l|}{ Vocational activities at Time 1 (from Vocational Index) } \\
\hline No activities & 21 & $13.0 \%$ \\
\hline Volunteering or non-degree seeking education only & 9 & $5.6 \%$ \\
\hline Sheltered setting only & 68 & $42.2 \%$ \\
\hline Sheltered setting and community employment & 19 & $11.8 \%$ \\
\hline Supported employment (no sheltered setting) & 29 & $18.0 \%$ \\
\hline Competitive employment or post-secondary education & 15 & $9.3 \%$ \\
\hline
\end{tabular}

Note. ADI-R = Autism Diagnostic Interview-Revised. SIB-R = Scales of Independent

Behaviors - Revised. Percentages in parentheses are the percentages of valid values in each category. 


\section{Attrition Analyses}

All of the 161 sample members provided Time 1 data. Data were available for 146 families (90.7\%) at Time 2, $136(84.5 \%)$ at Time 3, and $115(71.4 \%)$ at Time 4, $102(63.4 \%)$ at Time 5, and $91(56.5 \%)$ at Time 6. Over the course of the study, there were 11 cases in which the participating parent died or was no longer able to participate due to health problems, and primary study participation was assumed by a sibling or in two cases by a nonrelative guardian of the adult with ASD. Previous analyses have shown that our method of data collection is robust in the instance of such change in reporter (e.g., Manner et al., 2013).

Families who continued to participate over the study period $(n=91)$ were compared to those who did not complete all data collection points $(n=70)$ on a number of variables. There were no significant differences between groups in the age of the adult with ASD, his/her sex, ID diagnosis, verbal versus non-verbal status, proportion living with parents, maladaptive behaviors, number of services received, number of unmet service needs, independence in activities of daily living, family household income, parental age, parental race, parental education, parental marital status, and size of parental support network. There was also no difference between those who completed all data collection points and those who did not in the dependent variable (Vocational Index scores) at Time 1. The only variable that was significantly different between groups was autism symptoms; those who remained in the sample had more autism symptoms (e.g., more severe autism) compared to those who dropped out of the study, $t(159)=2.29, p=.02$. (Data are available from the first author.) Although we present these analyses to better understand the nature of study participation, it is important to note that our longitudinal models included all 161 participants. 


\section{Additional Results}

\section{Descriptive Statistics}

Means and standard deviations for the Vocational Index scores and within-person, timevarying predictors at each time point are presented in Supplemental Table 2. Visual examination of the means suggested a great deal of mean-level stability in measures, although Vocational Index scores were slowly decreasing, and both maladaptive behaviors and autism symptoms appeared to be improving slightly (decreasing in severity) over the study period. Somewhat more adults with ASD were living away from their families over time. Note, however, that these overall average patterns may obscure individual differences, which are the focus of the present study and are modeled below. Correlations between the between-persons variables are presented in Supplemental Table 3. 
Supplemental Table 2

Means and Standard Deviations for Within-Persons Variables by Wave of Measurement

\begin{tabular}{|c|c|c|c|c|c|c|c|c|c|c|c|c|}
\hline \multirow[b]{2}{*}{ Variable } & \multicolumn{2}{|c|}{ Time 1} & \multicolumn{2}{|c|}{ Time 2} & \multicolumn{2}{|c|}{ Time 3} & \multicolumn{2}{|c|}{ Time 4} & \multicolumn{2}{|c|}{ Time 5} & \multicolumn{2}{|c|}{ Time 6} \\
\hline & Mean & $S D$ & Mean & $S D$ & Mean & Mean & Mean & $S D$ & Mean & $S D$ & Mean & $S D$ \\
\hline \multicolumn{13}{|l|}{ Outcome } \\
\hline Vocational Index Score & 4.53 & 2.24 & 4.60 & 2.08 & 4.49 & 2.09 & 4.52 & 2.13 & 4.20 & 2.24 & 4.23 & 2.12 \\
\hline \multicolumn{13}{|l|}{ Time-Varying Predictors } \\
\hline Maladaptive Behaviors & 112.83 & 9.74 & 109.93 & 8.61 & 110.26 & 8.51 & 109.37 & 8.97 & 109.98 & 8.98 & 110.53 & 9.07 \\
\hline Autism Symptoms & 15.83 & 3.16 & 15.43 & 3.67 & 14.70 & 3.90 & 13.99 & 4.07 & 14.38 & 4.17 & 14.92 & 3.91 \\
\hline $\begin{array}{l}\text { Proportion Living } \\
\text { Outside of Parental Home }\end{array}$ & .60 & & .67 & & .66 & & .70 & & .74 & & .71 & \\
\hline $\begin{array}{l}\text { Total } N \text { with Vocational } \\
\text { Index Scores }\end{array}$ & \multicolumn{2}{|c|}{161} & \multicolumn{2}{|c|}{146} & \multicolumn{2}{|c|}{136} & \multicolumn{2}{|c|}{115} & \multicolumn{2}{|c|}{102} & \multicolumn{2}{|c|}{91} \\
\hline
\end{tabular}


Supplemental Table 3

Correlations between Level 2, Between-Persons Variables

\begin{tabular}{|c|c|c|c|c|c|c|c|c|c|c|c|}
\hline & 1. & 2. & 3. & 4. & 5. & 6. & 7. & 8. & 9. & 10. & 11. \\
\hline \multicolumn{12}{|l|}{ Personal Characteristics } \\
\hline 1. Intellectual Disability & -- & .15 & $.33 * *$ & $-.45^{* *}$ & -.08 & -.04 & $.26 * *$ & -.14 & -.06 & $.16^{*}$ & .09 \\
\hline 2. Maladaptive Behaviors & & -- & $.29 * *$ & $-.30 * *$ & .03 & $.16^{*}$ & $.35 * *$ & -.03 & -.08 & $-.34 * *$ & -.01 \\
\hline 3. Autism Symptoms & & & -- & $-.36 * *$ & $-.19 *$ & -.07 & $.21 * *$ & -.04 & .04 & -.01 & .03 \\
\hline 4. Independence in Activities of Daily Living & & & & -- & .03 & .06 & $-.33 * *$ & .04 & .08 & .06 & .10 \\
\hline 5. Sex $(1=$ Women $)$ & & & & & -- & -.07 & .02 & .05 & .08 & .06 & -.12 \\
\hline \multicolumn{12}{|l|}{ Contextual Resources } \\
\hline 6. Family Income & & & & & & -- & .01 & $-.18^{*}$ & .11 & $-.31 * *$ & .06 \\
\hline 7. Number of Services Received & & & & & & & -- & $-.50 * *$ & .06 & .00 & $.18 *$ \\
\hline 8. Number of Unmet Service Needs & & & & & & & & -- & -.12 & -.06 & $-.20 *$ \\
\hline 9. Number in Parent's Support Network & & & & & & & & & -- & .01 & -.03 \\
\hline \multicolumn{12}{|l|}{ Control Variables } \\
\hline 10. Age & & & & & & & & & & -- & $.20 *$ \\
\hline 11. Lives Outside of Parental Home & & & & & & & & & & & -- \\
\hline
\end{tabular}




\section{Further Analyses for Aim 1}

The findings from the HLM model, suggesting average decline in Vocational Index scores over time, were confirmed descriptively when examining the individual slopes estimated by this model: $76 \%$ of the adults with ASD had negative slope scores indicating decline in the Vocational Index over time, and $24 \%$ had positive slopes indicating improvement. Using a more stringent definition of change, $13.3 \%$ of adults had estimated slope scores indicating a decline in Vocational Index scores of at least one category over the study period. Fewer than 5\% (4.7\%) had slopes indicating improvement of at least one category over the study, and the remaining $82 \%$ had slope scores indicating stability.

\section{Follow-up Analyses for Aim 3}

In order to determine whether women in this sample were different from men in ways that might explain their greater average decline in Vocational Index scores over time, we ran independent samples t-tests and chi-squares comparing women to men in: age, sex, ID diagnosis, verbal versus non-verbal status, proportion living with parents, maladaptive behaviors, number of autism symptoms, number of services received, number of unmet service needs, independence in activities of daily living, family household income, parental age, parental race, parental education, parental marital status, and size of parental support network. Only one significant difference emerged; relative to men, women with ASD had fewer impairments in social reciprocity (a subtype of autism symptoms), $t(159)=2.50, p=.01$. 